\title{
La producción de vacunas contra el COVID-19 como insumo para la competitividad del sector farmacéutico argentino.
}

\section{The production of vaccines against COVID-19 as an input for the competitiveness of the Argentine pharmaceutical sector.}

ARTÍCULO

\section{Mariana Cuello \\ Universidad Nacional de Quilmes, Argentina. Contacto: mariana.cuello@unq.edu.ar}

Recibido: junio de 2021

Aceptado: agosto de 2021

\section{Resumen}

La pandemia por el COVID-19, ha encendido las alarmas sanitarias en todo el mundo, impulsando a los principales laboratorios farmacéuticos a un rápido desarrollo de vacunas para luchar contra el virus. Los países desarrollados acuñaron las primeras vacunas lanzadas al mercado, aventajando a la periferia no sólo en la producción de estos medicamentos sino además en el reparto. Sin embargo, dentro del grupo de países de la periferia, Argentina ha logrado celebrar convenios de producción local de vacunas producidas en los países desarrollados. No debe ignorarse que Argentina compone uno de los países de la región con importantes capacidades de producción local y exportación. En esta línea, en este trabajo se examinan las posibilidades que representa la producción local de vacunas contra el COVID-19, como un instrumento de competitividad del sector farmacéutico argentino, a partir de determinados vectores de competitividad y de las proyecciones que el sector ha realizado para 2025, en un escenario previo a este fenómeno mundial.

Palabras clave: vacunas COVID-19, sector farmacéutico, competitividad argentina.

\section{Abstract}

The COVID-19 pandemic has set off health alarms around the world, prompting major pharmaceutical laboratories to rapidly develop vaccines to fight the virus. Developed countries produced the first vaccines, leading the periphery not only in the production of these drugs but also in distribution. However, Argentina has signed local production agreements for vaccines produced in developed countries. It should not be ignored that Argentina is one of the countries in the region with local production and export skills. Considering this capabilities, this work examines the possibilities that local production of vaccines against COVID-19, represent as an 
instrument of competitiveness of the Argentine pharmaceutical sector, based on certain vectors of competitiveness and the projections that the sector has made for 2025 , in a scenario prior to this global phenomenon.

Keywords: COVID-19 vaccines, pharmaceutical sector, argentine competitiveness.

\section{Introducción}

Para fines de diciembre del 2019, en la ciudad de Wuhan, China, se identificó un nuevo coronavirus al que se lo denominó COVID-19. Frente a su gran expansión y gravedad, el 11 de marzo de 2020, la Organización Mundial de la Salud (OMS) lo declaró como pandemia. La expansión del virus en Europa primero y posteriormente en el continente de América, impulsó la acción de los países con más fuerza, con el propósito de contener la expansión del virus a la población. Ante esta pandemia, los países han aplicado diversas medidas para contener la expansión del virus.

En Argentina el primer caso confirmado fue el 3 de marzo 2020, y desde ese entonces, el número de contagios fue creciendo, aunque se implementaron inmediatamente medidas para su prevención, siendo el aislamiento social preventivo y obligatorio, desde el 20 de marzo 2020 , la de mayor impacto social. En este marco, rápidamente la comunidad científica colaboró con el estudio del fenómeno que iba cobrando cada vez más magnitud, y con el desarrollo de vacunas de la mano de algunos de los laboratorios más importantes de todo el mundo. La vacuna apareció como la solución más prometedora para combatir la pandemia, generándose una verdadera carrera científica para alcanzar en el menor tiempo posible, una vacuna segura y eficaz. A un año y medio del inicio de la pandemia, ya se encuentran aplicando un total de seis vacunas, que, aun estando en fase III de su desarrollo, las condiciones de emergencia mundial, han impulsado su aprobación para su uso.

Habiendo avanzado con el desarrollo de vacunas, el aprovisionamiento mundial se ha convertido en un gran desafío para los laboratorios, dado que la enorme demanda no podría ser cubierta por los mismos en su totalidad y en la velocidad que la pandemia requiere, lo cual ha impulsado a la firma de convenios de cooperación. Estos convenios han alcanzado a los países en desarrollo, entre ellos Argentina, que se han destacado por su capacidad de producción, por las facultades de imitación e incluso por la posibilidad de exportar. Actualmente, Argentina tiene vigente un acuerdo para la producción de la vacuna AstraZeneca en su principio activo, la Sputnik $V$ en su fase de formulación y envasado, y recientemente la Sinopharm, también para encargarse de las últimas etapas de producción. Por lo tanto, este artículo reflexionará si la producción local de estas vacunas puede colaborar como un insumo para la competitividad del sector farmacéutico argentino. Para alcanzar este propósito, la investigación se estructura de la 
forma siguiente: se inicia con el abordaje del marco teórico de referencia del trabajo, para luego avanzar sobre la descripción de la metodología adoptada en la investigación, describiéndose las técnicas implementadas. A continuación se avanza sobre el encuadre del estado del sector farmacéutico argentino previo a la pandemia, primero examinando el panorama general de la región y luego focalizando en el caso de Argentina, en virtud de la descripción de determinados vectores de competitividad basados en el marco teórico adoptado en el trabajo. Luego se arriba a la descripción de los acuerdos actuales de producción de vacunas para combatir el Covid-19 para proceder a reflexionar, en base a las proyecciones del sector, y el estado previo a la pandemia antes descripto, la potencialidad de la producción local de vacunas abierta por estos acuerdos y los desarrollos que conllevan, para impulsar la competitividad de la industria farmacéutica argentina.

\section{Algunos apuntes teóricos sobre competitividad.}

El concepto de competitividad resulta bastante amplio y complejo. Según la Comisión Económica para América Latina y el Caribe (CEPAL, 1995) "en la mayoría de los casos, no se da una definición muy exacta de competitividad y no se hace énfasis en el trabajo de medición ni en la importancia de los indicadores utilizados". En línea con ello, Porter (1990) señala que "no existe una definición de competitividad ni una teoría de la misma para explicarla que sean generalmente aceptadas", aunque reconoce que su significado puede variar cuando se habla de una empresa, una nación o según la especialidad o enfoque que lo defina. A pesar de estas dificultades, vale referir que el concepto ha logrado evolucionar en el tiempo a partir de diversas visiones que lograron aportar más precisión. Desde las primeras aproximaciones del concepto realizadas desde la teoría clásica, primero de la mano de Adam Smith y sus aportes sobre las ventajas absolutas, y luego con David Ricardo y las teorías de las ventajas comparativas que ponen eje sobre el comercio internacional, hasta la actualidad, se han enunciado valiosos aportes. En línea con la relevancia sobre rol de los mercados internacionales, Fajnzylber (1988), enlaza la competitividad a la capacidad de un país para "sostener y expandir su participación en los mercados internacionales, y elevar simultáneamente el nivel de vida de su población. Esto exige el incremento de la productividad y, por ende, la incorporación de progreso técnico". Otra de las clasificaciones que más ha influido en la literatura, se trata de aquella que define la competitividad en relación a la firma o industria, y a la nación como un todo. Esta clasificación ha sido analizada por Chudnovsky y Porta (1990). Asimismo, éstas y otras definiciones han puesto el eje en explicar la competitividad a partir de la dotación de factores de la producción, las economías de escala, o el comercio internacional. Más adelante, siguiendo a Doryan y otros (1999), han surgido nuevas líneas de investigación sobre la competitividad que buscan superar 
estas explicaciones, aportando que las variables explicativas de la competitividad pasan a ser la investigación y desarrollo de nuevas tecnologías de producción, la iniciativa empresarial, la inversión en capital humano, el conocimiento, las interrelaciones productivas, el learning by doing, etc. Sin embargo, ya desde la Organización para la Cooperación Económica y el Desarrollo (OCDE), se venían sistematizando nuevos aportes en esta línea, en lo que se denominó "competitividad estructural" (OCDE, 1992). El elemento central de este concepto es, por tanto, el énfasis en la innovación como factor primordial del desarrollo económico y el logro de la competitividad, donde intervienen el aprendizaje y la innovación en todas las áreas de una empresa, así como también influyen la conformación de redes de colaboración orientadas a la innovación y apoyadas en instituciones y un contexto institucional con capacidad para fomentar la innovación (Esser y otros, 1996).

El enfoque de competitividad estructural asimismo, se erige sobre la clásica distinción entre países del centro y de la periferia. Tal como las teorías ligadas al estructuralismo pregonan, la distinción entre centro y periferia, radicaba en que esta última era incapaz de absorber los frutos del progreso técnico, debido a su estructura productiva orientada a la exportación de productos primarios, frente a un centro productor y exportador de bienes industrializados, cuya estructura productiva le permite absorber el progreso técnico (Prebisch, 1948). Ello también se encuentra fundado en el hecho de que la periferia produce y exporta esencialmente bienes primarios, con escaso contenido tecnológico, mientras que el centro produce y exporta bienes industrializados con mayor densidad tecnológica. Con ello, la tecnología aparece como un factor clave en el desarrollo de las economías y, en este sentido, una fuente de competitividad, que debe ser considerada especialmente en la relación centroperiferia.

La base teórica de este trabajo por lo tanto, se puede sintetizar a partir de los principales rasgos que se describe en el Cuadro 1.

\section{Cuadro 1. Principales rasgos de la competitividad según autor.}

\begin{tabular}{|l|l|}
\hline Rasgos de la competitividad & Autores \\
\hline La capacidad de un país para a mediano y & Fajnzylber (1988) \\
largo plazo, sostener y expandir su & \\
participación en los mercados internacionales & \\
a la vez que se eleva simultáneamente. Ello & \\
exige el incremento de la productividad y, por & \\
ende, la incorporación de progreso técnico. & \\
\hline La capacidad para sostener e incrementar la & Porter (1990) \\
participación en los mercados & \\
internacionales, en consonancia con un & \\
\hline
\end{tabular}




\begin{tabular}{|l|l|l|}
\hline aumento del nivel de vida de la población, & \\
mediante el aumento de la productividad. & \\
\hline El énfasis en la innovación como clave para & Esser y otros (1996) \\
desarrollo económico y el logro de la & \\
competitividad, al cual deben contribuir: una & \\
organización empresarial con eje en & \\
potenciar el aprendizaje continuo y la & \\
innovación en todas las áreas de una & \\
empresa, las redes de colaboración & \\
orientadas a la innovación y apoyadas por & \\
diversas instituciones orientadas a fomentar & \\
la innovación y los conocimientos. & \\
\hline
\end{tabular}

Fuente: elaboración propia en base a Otero (2006) y Tapias Garcia (2005).

De manera sintética, por lo tanto, se pueden extraer de esta descripción como rasgos predominantes de la competitividad al comercio internacional, el nivel de producción y el énfasis en la innovación. Estos elementos guiarán el análisis de esta investigación y servirán de base para alcanzar los propósitos de la misma.

\section{Metodología.}

El propósito del presente trabajo es analizar las oportunidades del sector farmacéutico de Argentina para mejorar su competitividad, reflexionando en base al estado de sus principales indicadores de desempeño anterior a la pandemia, y los avances actuales en relación a la producción local de vacunas para combatir el COVID-19. En este sentido, la investigación se basa en el método de caso (Carson y Higgs, 1986; Neiman y Quaranta, 2006), combinando técnicas cualitativas y cuantitativas de investigación (Castro, 1999), sirviéndose de la triangulación de datos (Staslejko y otros, 2009), que se describen a continuación.

\section{Datos}

La información utilizada en este trabajo se compone esencialmente de artículos académicos, libros, capítulos de libros, artículos periodísticos y consultoras, y se complementa con datos provenientes de la Cámara Industrial de Laboratorios Farmacéuticos Argentinos (CILFA), que brinda información sobre un universo de 230 plantas manufactureras. Con ello, la investigación se define como un estudio cualitativo basado en los materiales académicos antes mencionados, combinado con técnicas cuantitativas, sobre los datos provenientes de CILFA respecto al estado anterior a la pandemia del sector farmacéutico, y las proyecciones que en 2019 la Cámara ha elaborado para 2025 aunque en un contexto previo a la pandemia, por lo 
tanto sin poder haberse anticipado a las condiciones del escenario extraordinario actual. Los materiales implementados en la investigación se han analizado y triangulado en torno a lo que en este trabajo denominaremos vectores de competitividad, definidos a partir de los rasgos de competitividad desarrollados en nuestro marco teórico (Cuadro 1), centrándose en el estudio de caso del sector farmacéutico de Argentina:

\section{Cuadro 2. Vectores de competitividad de análisis del sector farmacéutico argentino, previo a la pandemia.}

\begin{tabular}{|l|l|}
\hline Vectores & Indicadores \\
\hline Participación en los mercados & $\begin{array}{l}\text { Exportaciones e importaciones en base a } \\
\text { Nomenclatura Común del Mercosur 30, } \\
\text { internacionales } \\
\text { (CILFA, 2020). }\end{array}$ \\
\hline Nivel de producción & $\begin{array}{l}\text { Evolución de la producción en unidades y en } \\
\text { dólares, nivel de facturación (CILFA, 2020). }\end{array}$ \\
\hline Énfasis en la innovación & $\begin{array}{l}\text { Inversión en I+D, producción de activos (CILFA, } \\
2020) .\end{array}$ \\
\hline
\end{tabular}

Fuente: elaboración propia.

El examen del estado del sector farmacéutico previo a la pandemia comprenderá un insumo clave para reflexionar sobre el potencial que los recientes contratos para la producción de vacunas para combatir el COVID-19 a partir de las características de los mismos. Dicha reflexión se servirá entonces no sólo del análisis del estado del sector previo a la pandemia a partir del procesamiento de datos provenientes de CILFA en virtud de los vectores de competitividad referidos en el Cuadro 2, sino además de los rasgos de los contratos recientes firmados por Argentina, y particularmente de las fases del proceso productivo que Argentina tiene a cargo a partir de dichos acuerdos, que se pueden clasificar en las siguientes:

Diagrama 1: Fases de la producción de vacunas. 


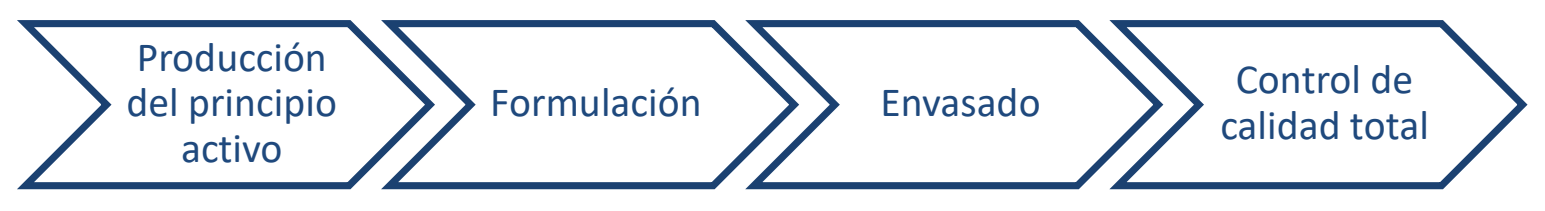

Fuente: elaboración propia en base a Marin Loaysa (2021) y Reolon (2009).

A partir de la definición de las fases que Argentina tiene a cargo, se reflexionará sobre el potencial de las mismas para impactar positivamente en los vectores de competitividad antes descripto. Asimismo, dicha reflexión será nutrida por las proyecciones que el sector ha hecho para el año 2025 y los primeros datos de resultado correspondientes a 2021, provenientes de consultoras y especialistas.

\section{El estado del sector farmacéutico en la región y en Argentina.}

Antes de abordar las características del sector farmacéutico de Argentina anterior a la pandemia actual, es pertinente referir primero a la región. Según un estudio de las Naciones Unidas, las farmacéuticas de México, Argentina, Brasil entre otras, se destacan entre los países de la periferia por contar con facultades de imitación de productos farmacéuticos novedosos, por su capacidad para poder cubrir la demanda interna de medicamentos y además exportar (Guzmán y Pluvia Zuñiga, 2004). Incluso, por su potencial para competir con los grandes laboratorios de los países desarrollados (Cuello, 2021). Al observar el Gráfico 1, podemos notar cómo este destaque se condice con los niveles de ventas de medicamentos para el año 2019 , que ubica a estos tres países en los primeros puestos.

Gráfico 1. Ventas en MM de unidades para América Latina, año 2019. 


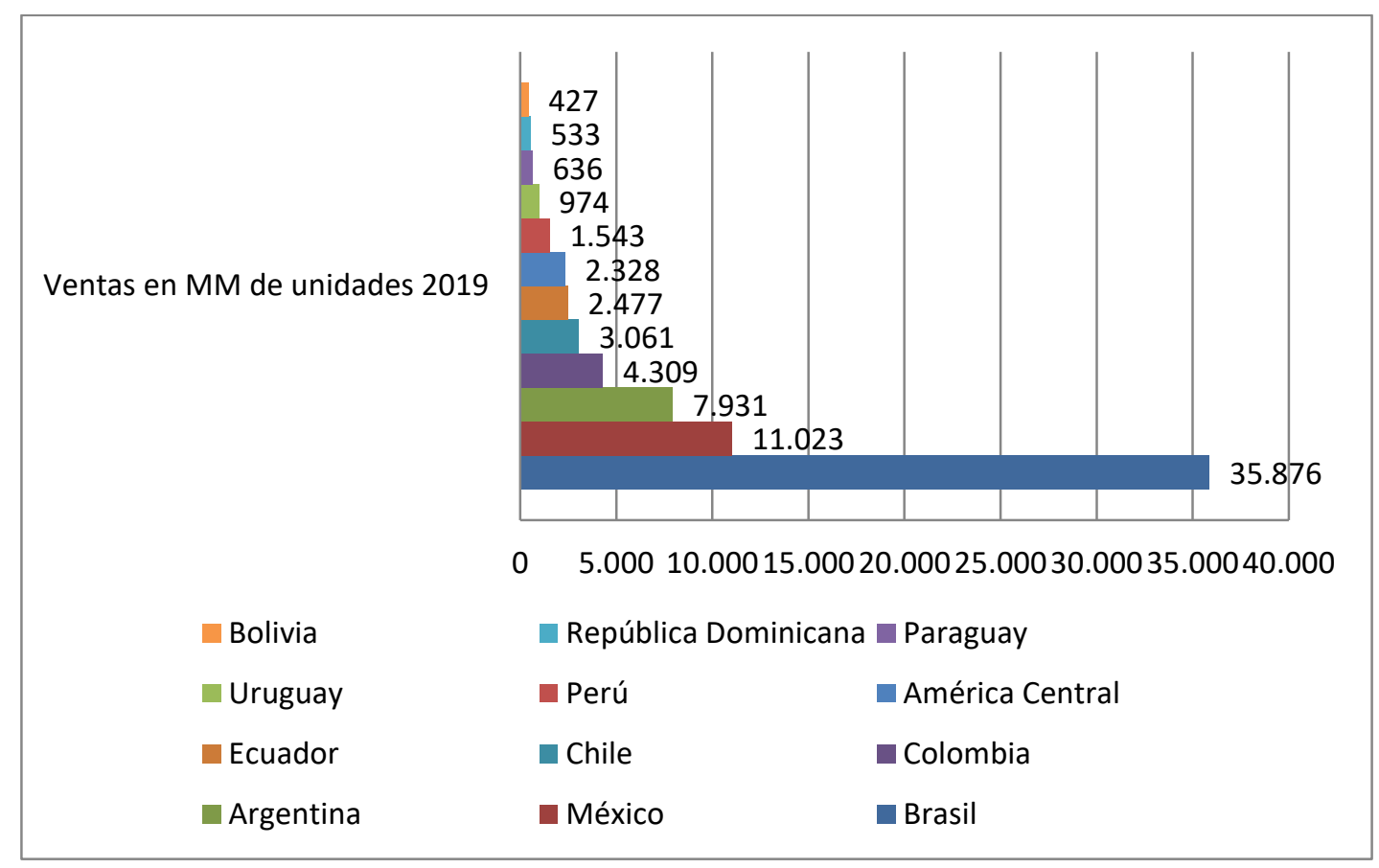

Fuente: elaboración propia en base a CILFA.

Por lo tanto, no es de extrañarse que precisamente estos tres países hayan firmado convenios de colaboración productiva con los países del centro, para la producción de vacunas para combatir el coronavirus.

\subsection{El estado de la industria farmacéutica argentina previo a la pandemia. Un análisis sobre los principales vectores de competitividad.}

En este apartado nos dedicaremos a abordar el análisis del estado del sector farmacéutico argentino a partir de los vectores de competitividad, abarcando un contexto previo a la pandemia que va desde el año 2005 hasta 2019, y se encuentran basados los datos que provee CILFA. Siguiendo a Cuello (2021), comenzaremos primero refiriendo a determinadas características del sector, que según la autora en las últimas décadas se ha configurado a partir de una importante presencia del capital nacional, frente a una menor participación del capital extranjero, a diferencia de lo que ocurre en otros países de la región como Brasil y México. Esta tendencia hacia la preeminencia del capital nacional se observa con el Cuadro 3 que ilustra la composición del sector para 2019 a partir de los datos de CILFA: 


\section{Cuadro 3. Composición del sector año 2019.}

\begin{tabular}{|c|r|}
\hline \multicolumn{2}{|c|}{ Composición del sector } \\
\hline Laboratorios & 354 \\
\hline Plantas manufactureras & 230 \\
\hline$-\quad$ Capital nacional & 182 \\
\hline$-\quad$ Multinacionales & 48 \\
\hline
\end{tabular}

Fuente: elaboración propia en base a CILFA.

En cuanto a la ocupación actual de personal en forma directa es de 43.000 personas, y en forma indirecta de aproximadamente 120.000. Cabe destacar la presencia de una alta proporción de personal de alta capacitación en el sector, destacándose técnicos y graduados universitarios de distintas profesiones, que según CILFA (2020) es relativamente mayor que en otros sectores.

Avanzando sobre el vector de competitividad nivel de producción, cabe destacar que el mercado total del sector ha mostrado un crecimiento en los últimos años, medido fundamentalmente en pesos, tal como se representa en el Gráfico 2. Aunque debe tenerse en cuenta la variación del tipo de cambio ocurrida durante el período analizado. En unidades totales ${ }^{1}$, el año de mayor registro ha sido 2017 con 740, 5 millones de unidades aunque desde 2005 que los valores no han bajado de las 500 millones de unidades de por año.

Grafico 2. Evolución del mercado total del sector, en millones de pesos y de dólares, período 2003-2019.

\footnotetext{
1 Según el Ministerio de la Salud de la Nación, el medicamento es "toda preparación o producto farmacéutico empleado para la prevención, diagnóstico y/o tratamiento de una enfermedad o estado patológico, o para modificar sistemas fisiológicos en beneficio de la persona a quien se le administra" (decr. 150/92 -texto ordenado, 1993-, art. $1^{\circ}$, inc. a) (Cantafio, 2017). Asimismo se puede tomar como sinónimo de productos farmacéuticos. A grandes rasgos, siguiendo la definición aquí señalada, los medicamentos se suelen clasificar en: medicamentos tradicionales, medicamentos y productos biológicos y biotecnológicos y productos farmoquímicos. Las vacunas se tratan de productos biológicos y/ biotecnológicos, según el caso.
} 
Divulgatio. Perfiles académicos de posgrado, Vol. 5, Número 15, 2021, 27-52 https://doi.org/10.48160/25913530di15.167

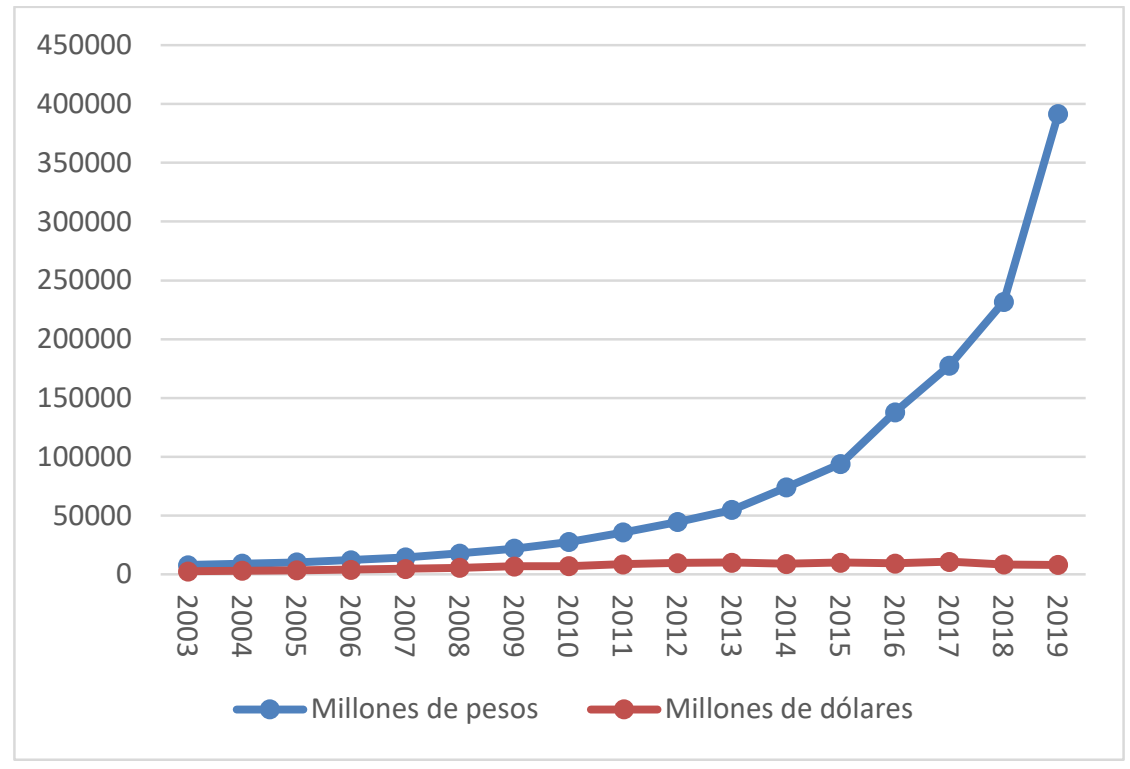

Fuente: elaboración propia en base a datos de CILFA.

La preeminencia del capital nacional mencionada anteriormente, también puede verse reflejada en la facturación para el año 2019, que se ilustra con los Gráficos 3 y 4, expresada en dólares.

Gráfico 3. Facturación de los laboratorios según capital, en millones de dólares (a precios mayorista) 2019.

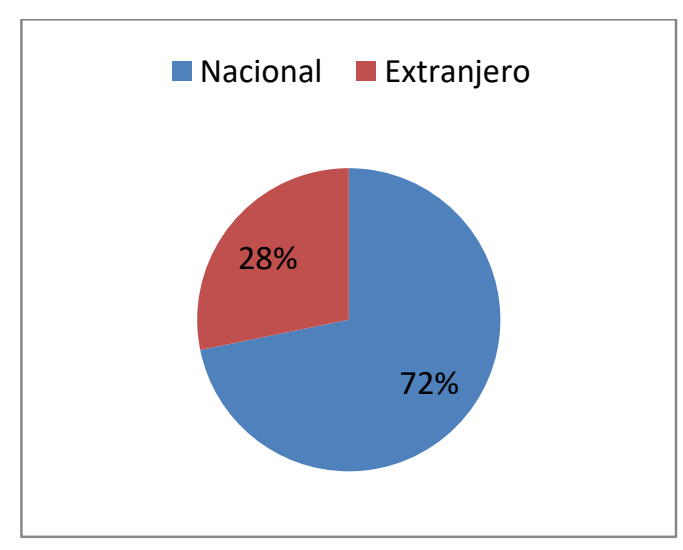

Fuente: elaboración propia en base a datos de CILFA. 


\section{Gráfico 4. Facturación de los principales laboratorios en Argentina, en millones de dólares (a precios mayorista) 2019.}

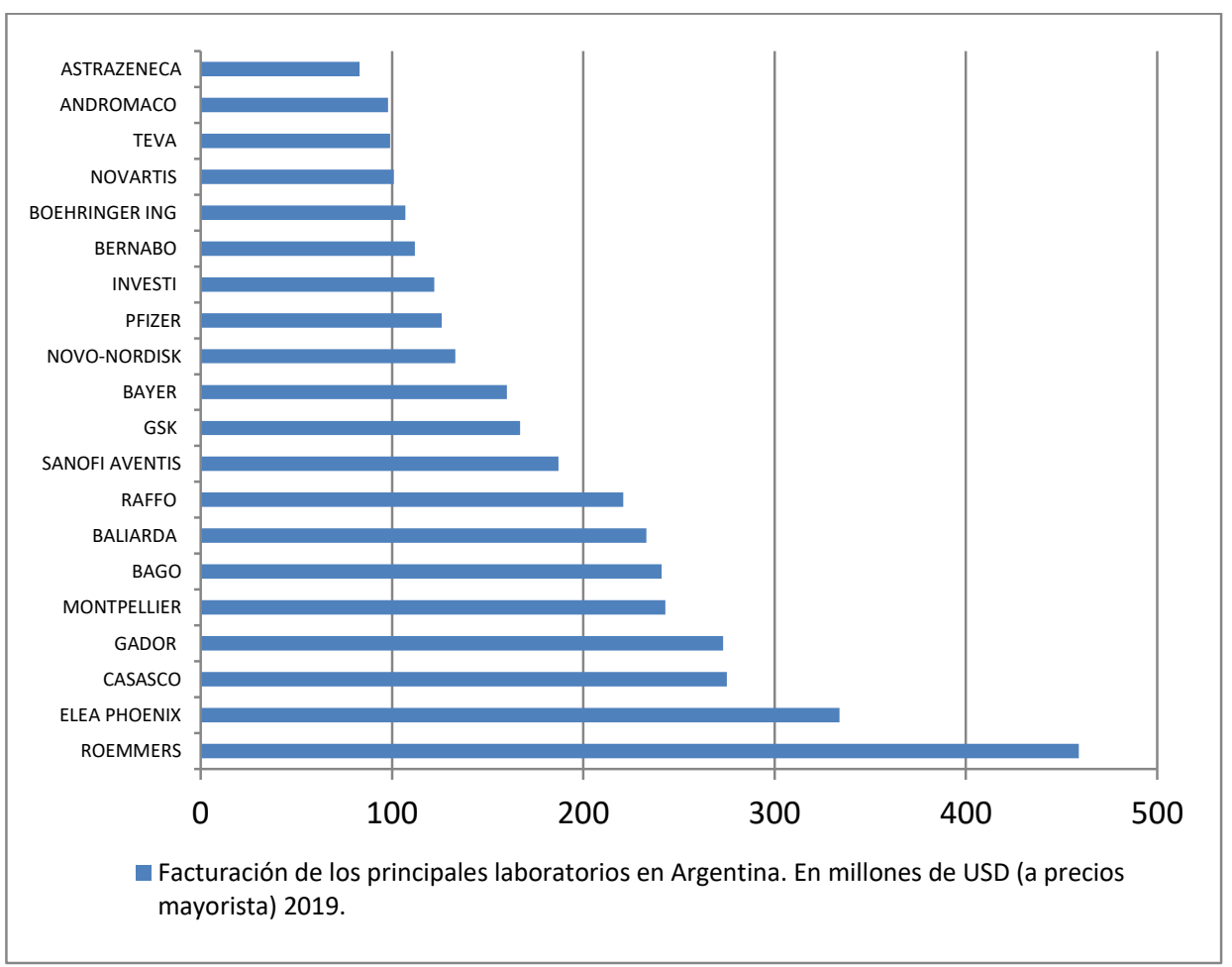

Fuente: elaboración propia en base a datos de CILFA.

En esta línea, según la información que se ilustra en el Gráfico 4 sobre la facturación de los principales laboratorios para 2019, cabe destacar que los primeros 10 puestos representan el $47 \%$ del total de la facturación y de ellos los primeros 8 se tratan de laboratorios nacionales.

Para analizar el vector de competitividad participación en los mercados internacionales, nos introducimos a examinar el saldo comercial del sector, que muestra grandes diferencias entre los laboratorios nacionales y extranjeros, en línea con la tendencia de los datos anteriores. 
Gráfico 5. Evolución de las exportaciones e importaciones de los laboratorios nacionales, capítulo 30 de NMC, en millones de dólares por año, período 2005-2019.

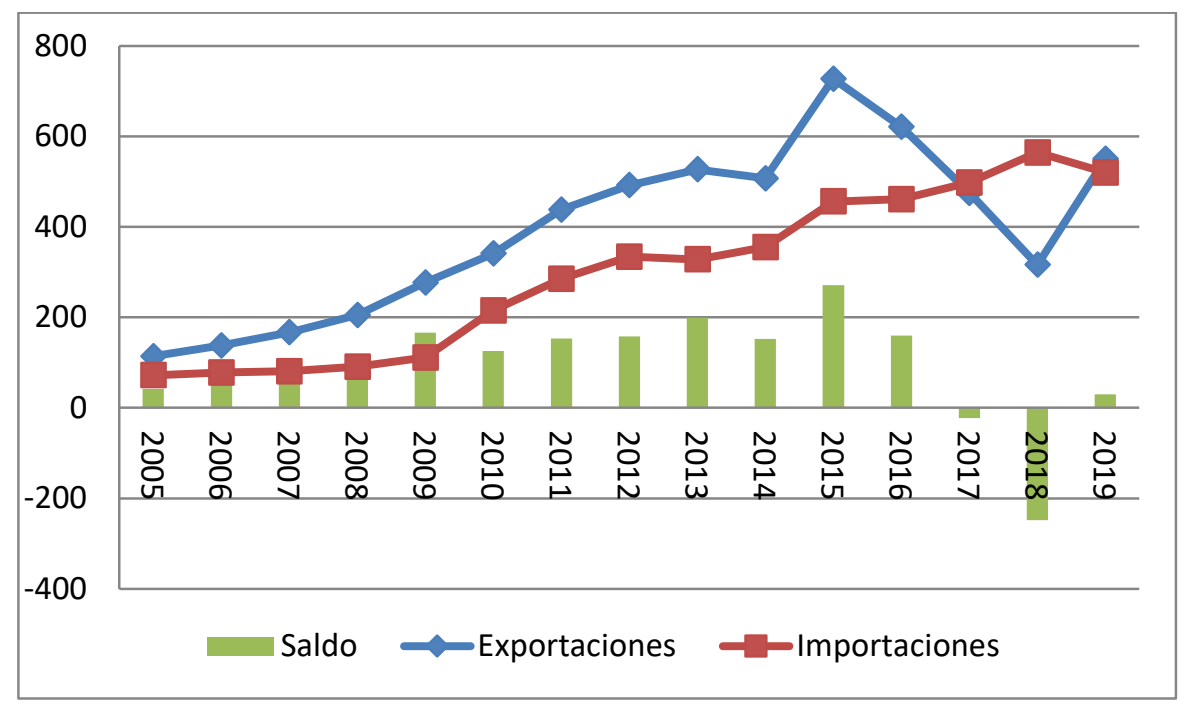

Fuente: elaboración propia en base a datos de CILFA.

Excepto los últimos tres años, a lo largo del período analizado los laboratorios nacionales mantuvieron siempre un saldo comercial positivo. La caída en las exportaciones según CILFA (2020) está estrechamente ligada a la reducción casi a cero de las exportaciones a Venezuela debido a la crisis económica y financiera del país. En cuanto a los laboratorios multinacionales, el saldo es deficitario durante todo el período, con una tendencia creciente. Cabe destacar que siguiendo la información provista por CILFA, el déficit se ve originado esencialmente en la importación de medicamentos biotecnológicos. Entre 2005 y 2019 el déficit se incrementa un $316 \%$, aunque en los años 2018 y 2019 hubo una mejora del saldo de la Balanza Comercial, en el último año la participación de los laboratorios en este déficit fue sólo del 4\% (Gráfico 6).

En cuanto a la composición de las exportaciones, para 2019 los laboratorios nacionales exportaron un $14,9 \%$ de productos farmoquímicos, mientras que un $85,1 \%$ de medicamentos. Por su parte, según datos del mismo año, los laboratorios multinacionales prácticamente sólo exportaron medicamentos (99, $8 \%$ ), frente a los farmoquímicos (0, 2\%) (CILFA, 2020). 
Gráfico 6. Evolución de las exportaciones e importaciones de los laboratorios extranjeros, en millones de dólares por año, período 2005-2019.

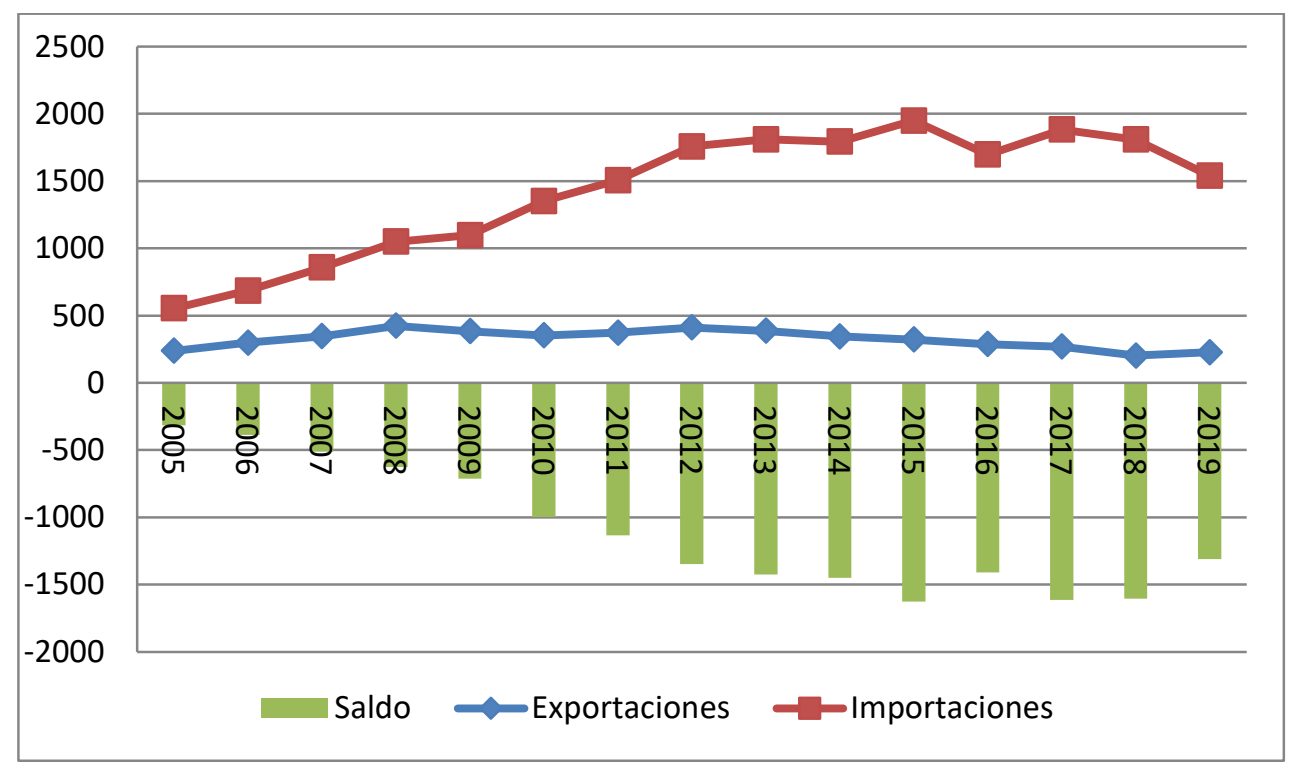

Fuente: elaboración propia en base a datos de CILFA.

En cuanto a los principales destinos de exportaciones del total de laboratorios del sector incluyendo tanto a los de origen nacional como extranjero, el Gráfico 7 muestra un importante sesgo hacia la región para 2019, siendo Uruguay el principal destino, con un $26 \%$ del total, y 118.9 millones de dólares secundado por Brasil que con 91,7 millones de dólares representa el $20 \%$. En tercer puesto se ubica a Paraguay con un $11 \%$ (52,3 millones de dólares). Por lo tanto para 2019 las exportaciones hacia el MERCOSUR explicaron un 36,7\% del total. Mientras tanto, el total enviado a América Latina explicó un $63,7 \%$.

Gráfico 7. Exportaciones totales del rubro farmacéutico de Argentina 2019, en dólares.

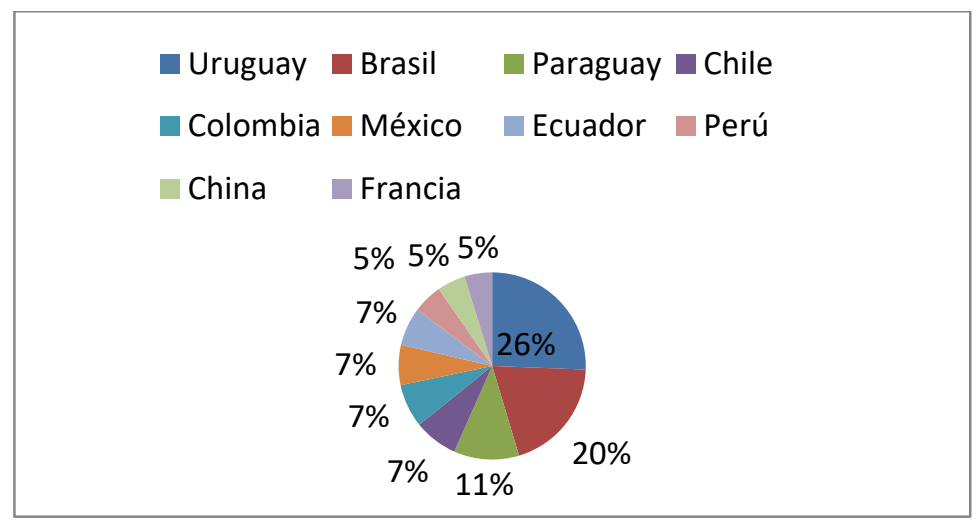

Fuente: elaboración propia en base a datos de CILFA. 
Gráfico 8. Importaciones totales del rubro farmacéutico de Argentina 2019, en dólares.

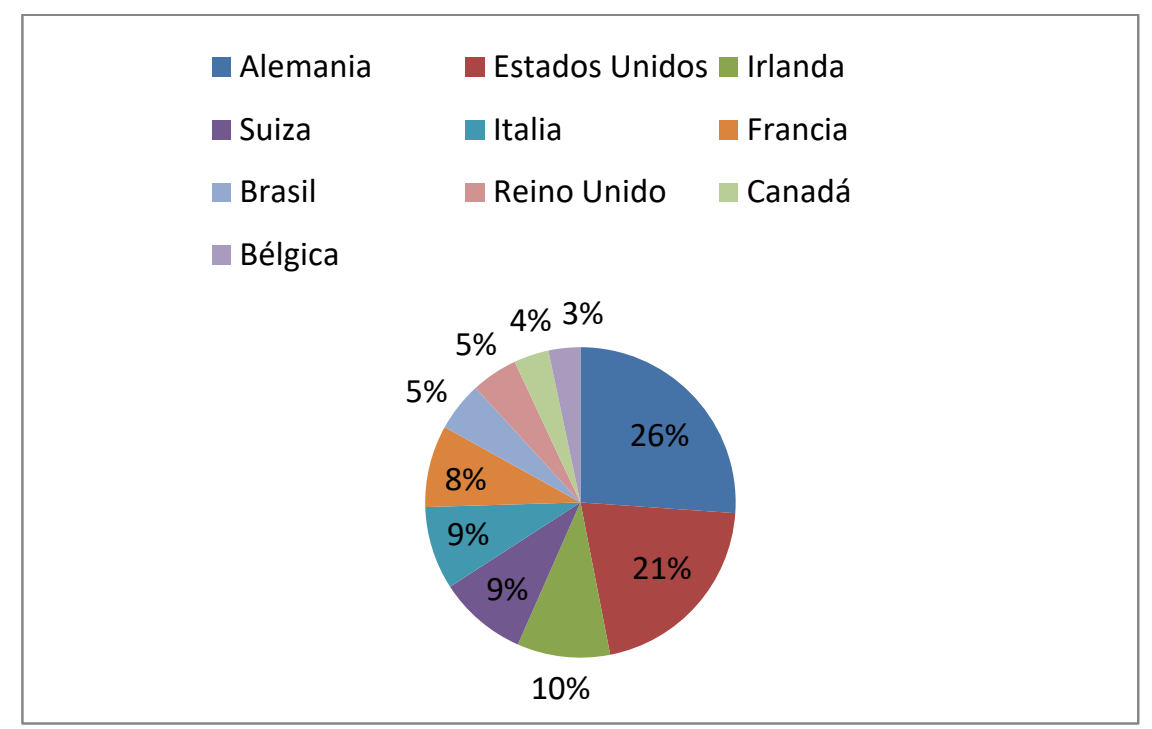

Fuente: elaboración propia en base a datos de CILFA.

Es interesante el contraste con las importaciones, donde, a partir del Gráfico 8, se observan los principales destinos, ubicándose en primer puesto a Alemania con el $26 \%$ (436,5 dólares), seguida por Estados Unidos con un 21 \% y 348,3 millones de dólares, y en tercer lugar por Irlanda con 161,9 millones de dólares y representa el $10 \%$. Debe destacarse que de la región sólo Brasil se encuentra entre los principales destinos de importación. Los productos más importados por el sector se trata de medicamentos con enzimas, preparaciones anticonceptivas, medicamentos con insulina y fracciones de la sangre como el plasma o plaquetas (Azpeitia Soto, 2019).

Pasando a examinar nuestro último vector de competitividad, el énfasis en la innovación, de acuerdo a CILFA (2020), el sector farmacéutico encabeza el podio de I+D en la Argentina, con una incidencia del $27 \%$ sobre el total de I+D privada en el país. Asimismo, para 2019, muestra un elevado grado de competencia en el mercado interno con un importante número de principios activos sobre el total de productos, tal como se observa en el Cuadro 4.

Cuadro 4: principios activos y participación del mercado para el sector farmacéutico argentino, año 2019.

\begin{tabular}{|l|l|l|l|}
\hline & \multicolumn{1}{|c|}{$\begin{array}{c}\text { Cantidad principios } \\
\text { activos }\end{array}$} & $\begin{array}{c}\text { Participación de } \\
\text { mercado }\end{array}$ & \multicolumn{1}{c|}{$\begin{array}{c}\text { Cantidad } \\
\text { Medicamentos }\end{array}$} \\
\hline Más de 10 productos & 140 & $55,58 \%$ & 3.059 \\
\hline $\begin{array}{l}\text { Entre 5 y 10 } \\
\text { productos }\end{array}$ & 228 & $20,04 \%$ & 1.672 \\
\hline
\end{tabular}




\begin{tabular}{|l|l|l|l|}
\hline $\begin{array}{l}\text { Menos de } \\
\text { productos }\end{array}$ & 118 & $24,38 \%$ & 1.525 \\
\hline
\end{tabular}

Fuente: CILFA (2020).

Según la información del Cuadro 4, podemos destacar que 140 principios activos representan el 55,58\% del mercado de las drogas que actualmente se comercializan en el mercado argentino y tienen una oferta superior a 10 productos distintos. Mientras que 228 principios activos (que representan el $20,04 \%$ del mercado) tienen una oferta de entre 5 y 10 medicamentos de diferentes laboratorios que compiten entre sí. Es decir que el $75,62 \%$ del mercado está compuesto por drogas cuya oferta es mayor o igual a 5 productos distintos, lo cual es un indicador de que hay un importante aporte del sector a la producción de principios activos, que se puede inferir como la fase de producción que mayor complejidad y aplicación de conocimientos requiere (Vielma y otros, 2018). Asimismo, vale destacar que para el mismo año, CILFA (2020) señala que la capacidad instalada es de un $80 \%$ sobre el total de laboratorios tanto de índole nacional como extranjero, lo cual es un indicativo de que hay espacio para continuar expandiendo la producción tanto de productos como de principios activos.

En línea con este análisis, según Cuello (2021), la industria farmacéutica argentina se ha destacado desde las últimas décadas por su capacidad de imitación de medicamentos, la producción de genéricos y una importante participación en el mercado interno y externo. Respecto al carácter innovativo, se destacan las innovaciones menores limitadas a las formulaciones de los medicamentos sobre la base de drogas existentes (Abrutzky y otros, 2015). En esta capacidad han influido según la autora, las disposiciones nacionales en torno a la propiedad intelectual. Según el Informe 301, Argentina presenta deficiencias en sus legislaciones de propiedad intelectual en torno a los productos farmacéuticos, reclamando por disposiciones más duras, dado que "rechaza las solicitudes de patentes para categorías de invenciones farmacéuticas, que en otras jurisdicciones, incluso en los Estados Unidos son materia de patentabilidad. Además, para ser patentable, Argentina exige que se divulguen los procesos para la fabricación de compuestos activos, cumpliendo la disposición de ser reproducible y aplicable a escala industrial" (United States Trade Representative, 2020: 60). Si bien Argentina ha adscrito al Acuerdo sobre Aspectos de propiedad Intelectual y Comercio (ADPIC) con la ley $\mathrm{N}^{\circ} 24.425$ del 7 de diciembre de 1994, presenta esas salvedades respecto a las recomendaciones del Informe 301, que la autora expone como oportunidades para nutrir las capacidades locales. Asimismo, con la llamada "Ley de medicamentos" (ley N²5.649), sancionada en 2002 en un marco de crisis económica y social generalizada, se dio un impulso a la industria local de medicamentos y fundamentalmente de los genéricos, con el propósito de brindar acceso a medicamentos, considerándolo un bien esencial, lo cual la autora señala como otro elemento que ha definido las condiciones para el desarrollo de las capacidades imitativas 
y productivas del sector. Como tercer elemento, para el año 2012 se introdujeron algunos cambios en los criterios para el análisis y concesión de invenciones farmacéuticas con la Resolución Conjunta de los Ministerios de Industria y Salud y del Instituto Nacional de la Propiedad Intelectual (546/2012 y 107/2012, INPI N 118/2012, respectivamente), definiéndose el rechazo de solicitudes de patentes farmacéuticas que reivindiquen composiciones, dosificaciones, sales, éteres y ésteres, polimorfos, procesos análogos, metabolitos y prodrogas, enantiómeros, invenciones de selección y reivindicaciones. Vale aclara que ello se definió en línea con las disposiciones del ADPIC que otorga a los países Miembros la potestad de determinar los estándares de novedad, y altura inventiva que deben cumplir las invenciones para constituir materia patentable, y además que estuvo en consonancia con la Declaración de Doha, que ratifica esta facultad en pos de los reclamos en torno a la salud pública expresados por los países en desarrollo.

Vale destacar entonces, que estos aspectos fueron definiendo un perfil productivo e innovativo más bien basado en mejoras o adaptaciones de productos y procesos existentes. Es importante señalar también que, durante el gobierno anterior, se han formulado propuestas para modificar las legislaciones nacionales en torno a la regulación de la propiedad intelectual del sector farmacéutico con miras a estandarizarlas con las disposiciones internacionales tanto del ADPIC, así como también para adscribir al Tratado de Cooperación en materia de Patentes $(P C T)^{2}$. ¿Qué implicancias tendría para el sector el ingreso al PCT? Según las visiones en contra, que provienen fundamentalmente de CILFA, con el ingreso al PCT las farmacéuticas internacionales podrán solicitar una mayor cantidad de patentes en Argentina, con lo cual se ahogaría el negocio de las empresas nacionales, y con ello la competencia. Por otro lado, también aducen que el PCT "solo sirve a los principales países desarrollados" y que su adopción significará perder la soberanía legislativa e independencia del sector. Las visiones a favor, que provienen esencialmente de los laboratorios extranjeros agrupados bajo CAEME, refieren que sería positivo ingresar al Tratado ya que implicaría una reducción de costos en los trámites de patentes en países extranjeros, dado que consiste en un único trámite que valida la patente en todos los países miembro del PCT, a diferencia del trámite por fuera del tratado, que debe realizarse país por país, implicando por lo tanto, un costo superior. La puja para la adhesión al PCT y el endurecimiento de las leyes nacionales de propiedad intelectual, se han aplacado en el marco del actual gobierno, dado que la crisis sanitaria global ha puesto en discusión las

\footnotetext{
2 Si bien el país firmó su adhesión el 21 de diciembre de 1970, en la práctica no se encuentra formalmente bajo su órbita. El proyecto para ingresar al Tratado fue presentado en 1998 y desde entonces cuenta con media sanción del Senado, aunque se estancó hasta hace poco, cuando el Tratado volvió a la agenda pública vinculada al propuesto Acuerdo Comercial entre el Mercosur y la Unión Europea (UE).
} 
verdaderas bondades de las disposiciones que promueve el ADPIC, el PCT y convenios anexos, con diversos reclamos provenientes principalmente de los países en desarrollo, frente a las dificultades de acceso a las vacunas para el COVID-19 --y demás medicamentos e insumos relacionados a la enfermedad--, ante la protección de patentes de las mismas. Sin lugar a dudas este tema resulta complejo y genera múltiples debates, con lo cual en próximos trabajos serán estudiados y analizados de manera más minuciosa.

\section{La emergencia sanitaria por la pandemia del COVID-19. Le generación de vacunas y el rol de los países de la periferia.}

Los esfuerzos en investigación que vienen realizándose en pos del desarrollo de vacunas contra el COVID-19, resultan de enorme magnitud. En tiempo récord se ha logrado avanzar en la generación y producción de vacunas, a la vez que se han erigido debates y controversias sobre el acceso a las mismas. Desde la OMS, quien de manera conjunta con la Comisión Europea y otras organizaciones como la Fundación Bill y Melinda Gates, rápidamente se ha expresado la importancia de la unión de los líderes mundiales para asegurar que todos puedan acceder a las vacunas, tests y tratamientos para el COVID-19. En esa línea, Moreira (2020) expresaba la importancia de la cooperación internacional para la producción y distribución de la vacuna a nivel global.

En cuanto al desarrollo de vacunas, los países del centro han tomado la delantera, aunque la periferia ha logrado ubicarse en un rol colaborativo con los países desarrollados. Al momento de redacción de este texto, los proyectos más avanzados son: BNT162 (Pfizer y BioNTech), mRNA-1273 (Moderna), AZD1222 (Universidad de Oxford y AstraZeneca), CoronaVac (Sinovac), Sputnik V (Centro Gamalaya de Investigación en Epidemiología y Microbiología), JNJ-78436735 (Johnson \& Johnson), NVX-CoV22373 (Sinopharm), Ad5-nCoV (CanSino), y Covaxin (BharatBiotech) (Cuello y otros, 2021). Todas estas vacunas se encuentran en Fase III de ensayos clínicos aunque, ante la situación de emergencia sanitaria mundial, ya han sido aprobadas y la mayoría están siendo aplicadas en diversos países.

Cabe destacar que, a pesar del rol que recientemente ha asumido la periferia para la colaboración en la producción de vacunas, ha sido una de las regiones que menos dosis de vacunas ha recibido. Según la base de datos desarrollada por la Universidad de Oxford "Our World in Data", América Latina ha recibido, hasta la fecha, algo más de un $2 \%$ del total de dosis aplicadas, en tanto que Europa concentró más del $25 \%$, América del Norte más del $30 \%$, y Asia, casi un $40 \%$ del total de vacunas (Our World in Data, 2021).

Los mecanismos de acceso a las vacunas se pueden clasificar en: las adquisiciones, los desarrollos locales, el mecanismo de distribución equitativa del Fondo de Acceso Global para 
Vacunas Covid-19 también conocido como COVAX, por sus siglas en inglés, que compone una alianza impulsada por actores públicos y privados para garantizar el acceso equitativo a las vacunas contra el COVID-19, y se integra actualmente por 190 países - entre ellos, Argentina,, o también, la fabricación en territorio propio con el consentimiento de las industrias farmacéuticas titulares de las licencias asociadas a las vacunas. La adquisición ha constituido el principal recurso implementado por la región para acceder a las vacunas, contando además con el mecanismo solidario de COVAX. El desarrollo local, que resultaría el mecanismo más promisorio para el acceso y para la generación de capacidades de producción e innovación local, se trata más bien de un recurso más a mediano y largo plazo, aunque la firma de contratos de colaboración de producción entre países desarrollados y algunos de la región, ha sido uno de los mecanismos que recientemente se han optado por acordarse para estos propósitos. A continuación se enunciarán aquellos firmados por Argentina, y se describirán las etapas de producción que cada acuerdo implica para el desarrollo local de las vacunas.

\section{Los contratos de la producción local en Argentina.}

Argentina, junto a México y Brasil, los países que hemos enunciando como aquellos con mayor capacidad de producción imitación y exportación de América Latina, han celebrado convenios con laboratorios de los países del centro para la producción de vacunas contra el COVID-19.

En el caso de Argentina, y recordando que la fabricación de una vacuna se puede dividir en cuatro fases: producción del principio activo, formulación, envasado y control de calidad final, se pueden describir los acuerdos vigentes y las fases a cargo del país, según cada convenio. Actualmente se destacan tres iniciativas de producción: la correspondiente a los laboratorios de Oxford-AstraZeneca, Sputnik V y Sinopharm ${ }^{3}$.

- Oxford-AstraZeneca: el laboratorio internacional MabXience se encarga de la fabricación del principio activo de la sueco-británica AstraZeneca en Argentina, en su planta en Garín, que luego es despachado a México para su envasado. Si bien se han generado cuellos de botella en la producción del envasado, actualmente se ha normalizado a producción, con un acuerdo para distribuir a precios accesibles hasta 250 millones de dosis en la región (Devicenci, 2020).

- Sputnik V: el laboratorio nacional Richmond llegó a un acuerdo con el Fondo Ruso de Inversión Directa (RDIF) a fines del mes de abril para fabricar la vacuna rusa Sputnik V.

\footnotetext{
${ }^{3}$ En adelante nos referiremos a las vacunas según el nombre de los laboratorios internacionales que las generaron y no según su nombre genérico según detallamos en la página anterior, dado que resultan identificables por el nombre del laboratorio más que por el nombre del producto.
} 
El laboratorio local recibió el principio activo para fabricar la vacuna del instituto Gamaleya y se encuentra avanzando rápidamente en el proceso de producción, estimando que tendrá la capacidad para producir 500 mil dosis semanales, pero el objetivo es alcanzar 5 millones por mes. Es menester resaltar que el acuerdo ha contado con un gran apoyo e impulso de parte del gobierno nacional, generando grandes expectativas sobre las posibilidades de abasatecimiento que abre la producción local (Klipphan, 2021). Por otro lado, cabe mencionar que el laboratorio argentino se encargará de la formulación y envasado de la vacuna, aunque tiene como objetivo para 2022 también fabricar el principio activo (Centenera, 2021).

- Sinopharm: Sinergium Biotech, una empresa de las familias Bagó, Sielecki, Gold y Sigman es la que se encargará de fabricar la vacuna china Sinopharm, cuyas negociaciones están recientemente resueltas para iniciar el proceso. Sinergium fabrica anualmente más de 20 millones de vacunas contra la gripe (con transferencia de tecnología de Novartis), y además se encarga de la vacuna del Neumococo, por un total de 15 millones (para Pfizer), y la del papiloma humano (HPV), por 6 millones (para Merck) (Blanco, 2021). La planta en Argentina ya tiene 10 años de antigüedad, y es una de las más modernas de la región, según resaltan desde la compañía. La parte china hizo saber que podría enviar el principio activo en junio, posibilitando a la contraparte local encargarse de las fases siguientes del proceso de producción.

Por lo tanto, en Argentina la iniciativa de la vacuna de AstraZeneca es la única que se concentra en la fase inicial de producción del principio activo, mientras que la Sputnik $V$, que ya se encuentra fabricando y la Sinopharm, que recientemente se ha acordado, se centran en las fases siguientes de producción.

\section{El impulso para la competitividad argentina del sector farmacéutico. Reflexiones a partir de las proyecciones del sector.}

Con el anuncio de la fabricación a nivel nacional de las vacunas Sputnik V y AstraZeneca, y más recientemente con la Sinopharm contra el coronavirus, las proyecciones indican que para fin de año Argentina se convertirá en el noveno país del mundo en realizar este tipo de desarrollo. Estos datos son provistos por Evenitt y Linley (2021), de la consultora internacional Airfinity, que además señalan que los principales países productores de vacunas son China; Estados Unidos, India, Alemania y un bloque europeo compuesto por Bélgica y Países Bajos. Según aducen los autores, estas potencias habrán producido cada una al menos 1.500 millones de dosis hacia fin de año. China llegará casi a los 3.500 millones y Estados Unidos, a los 2.000 
millones. Luego sigue un lote de productores menores entre los que están Corea del Sur, Suiza, Reino Unido, Rusia y Argentina. Otros países de la región que figuran en el informe son Brasil y Cuba.

A diferencia de las primeras potencias de este ranking, Argentina no ha logrado obtener aún una fórmula propia desde cero. Sin embargo, los acuerdos para la producción de AstraZeneca, Sputnik V y Sinopharm pueden contribuir desde diversos aspectos con la competitividad del sector. Para analizar esta cuestión, primero referiremos a las proyecciones para 2025 que CILFA ha elaborado con anterioridad al surgimiento de la pandemia, con lo cual no ha considerado entonces los posibles efectos de los acuerdos de producción de vacunas anticovid en el sector.

\section{Cuadro 4. Proyecciones del sector farmacéutico argentino para 2025.}

\begin{tabular}{|c|c|c|c|c|}
\hline Variable & Unidad & 2019 & Objetivo 2025 & Comentarios \\
\hline $\begin{array}{l}\text { Facturació } \\
\text { n Total }\end{array}$ & $\begin{array}{l}\text { U\$S millones } \\
- \\
\text { a precios de } \\
\text { salida de } \\
\text { laboratorio }\end{array}$ & 5.363 & 6.150 & $\begin{array}{l}+14,6 \% \\
\text { Mejorar los índices de productividad } \\
\text { mediante inversiones en bienes de } \\
\text { capital, tras recuperación nivel } 2015 \\
\text { y mejora participación producción en } \\
\text { ventas }\end{array}$ \\
\hline $\begin{array}{l}\text { Ventas } \\
\text { internas }\end{array}$ & U\$S millones & 4.634 & 5.200 & Consolidación del mercado interno \\
\hline $\begin{array}{l}\text { Exportacio } \\
\text { nes }\end{array}$ & U\$S millones & 729 & 950 & $\begin{array}{l}+30,3 \% \\
\text { Mayor número de destinos y mejora } \\
\text { la diversificación de productos }\end{array}$ \\
\hline Empleo & Ocupados & $\begin{array}{l}43.00 \\
0\end{array}$ & 44.000 & $\begin{array}{l}\text { Incremento en } 1.000 \text { puestos de } \\
\text { trabajo de la mano de obra ocupada } \\
\text { en la industria. }\end{array}$ \\
\hline
\end{tabular}

Fuente: CILFA (2020).

Teniendo en cuenta que la emergencia sanitaria ha abierto un mercado para la producción y exportación de vacunas, es menester destacar que hay potencial para que los acuerdos vigentes tengan un impacto positivo en estas proyecciones, que de por sí, apuntan a una expansión del sector. Aunque cabe aclarar que lo laboratorios no se encuentran reducido a la producción de vacunas, sino a un universo más amplio de productos farmacéuticos.

Teniendo en cuenta los vectores de competitividad en los que este trabajo se ha centrado, se pueden ensayar las siguientes reflexiones: 
- Participación en los mercados internacionales: según se han expresado públicamente las autoridades nacionales, uno de los objetivos de la producción nacional de vacunas es no sólo abastecer al mercado nacional, sino además destinar a exportación. Teniendo en cuenta que el MERCOSUR es el principal mercado de Argentina en la materia, ello puede redundar en la generación de nuevos lazos con la región. Ello colaboraría con el aprovechamiento de la capacidad productiva de los laboratorios de capital nacional y extranjero, y posibles economías de escala, que redunden en una reducción de costos, y repercutan también favorablemente en el vector siguiente.

- Nivel de producción: la escala de producción del sector para las vacunas puede impulsar notablemente el sector, dada la emergencia actual para la provisión nacional y regional, mejorando además los indicadores de capacidad instalada ociosa, que según CILFA (2020), para 2019 se situaba en el $80 \%$.

- Énfasis en la innovación: si bien la vacuna de AstraZeneca es la única que se produce en sus principios activos, hay proyección para la Sputnik $V$ de producir también a nivel local estos antígenos, de manera de impulsar la generación de conocimientos a nivel local.

Examinando las fases de producción que los acuerdos vigentes en Argentina implican, se puede ensayar con qué vectores colaboraría cada uno:

- el acuerdo de producción local AstraZeneca colaboraría más con el tercer rasgo de la competitividad, es decir, con el énfasis en la innovación, dado que la producción local está orientada a ocuparse de la fase inicial de la vacuna, es decir, la producción del principio activo, lo cual como ya se ha referido con anterioridad representa una oportunidad para la generación de capacidades dado que implica un grado de complejidad nada despreciable.

- el acuerdo de producción local de Sputnik V harían lo propio con las otras dos características de competitividad, dado que se centra en las fases siguientes de producción ligadas a la formulación y envasado de la vacuna, y con ello a la producción, con lo cual podría impactar positivamente tanto en los niveles de producción del sector como también en la provisión a los mercados internacionales. Cuando se comience a producir el principio activo a nivel local, se avanzaría además con el vector énfasis en la innovación, según se describió anteriormente.

- $\quad$ el acuerdo de producción local de Sinopharm, también podría impactar en los niveles de producción y la participación en los mercados internacionales, como vectores de 
competitividad, dado que también está orientado a la producción local de la vacuna en sus últimas fases.

Por lo tanto, se puede esbozar que las proyecciones que CILFA definió para 2025 podrían verse impulsadas por estas iniciativas de producción local de vacunas que este escenario extraordinario ha dado lugar. Asimismo, si bien el sector no se ve limitado solamente a la producción de vacunas, se pueden enunciar las siguientes oportunidades que abren estos acuerdos para posicionarlo:

- Transferencia de tecnología: es valorable el aporte de la misma para la generación de capacidades locales, y la posibilidad de que, a partir de ellas se pueda contar con conocimientos que aporten a desarrollos propios, e incluso a la producción de otros medicamentos, que bien podría aplicarse para la proyección de 2025. Asimismo, teniendo en cuenta la capacidad imitativa del sector, y el rol preponderante de los laboratorios de capital nacional en la producción y aprovisionamiento nacional y regional, se abre una ventana de oportunidad para nutrir a estas industrias que ya contaban con gran capacidad imitativa, de mayores conocimientos.

- Eslabonamientos: se pueden generar nuevas oportunidades para las industrias encargadas de la producción de cualquiera de los insumos implementados en la fase de envasado, produciéndose un efecto positivo en la cadena de producción que incorpore a otras industrias en la cadena o mejore la posición de aquellas que ya se encuentran implicadas en el proceso productivo.

- Nuevos acuerdos: la celebración de los convenios vigentes y la materialización de la producción local, pueden dar lugar a la generación de nuevos acuerdos con otros laboratorios internacionales, no sólo para la producción de la vacuna anticovid, sino también para cualquier otro medicamento, con la posibilidad de repercutir en todos los vectores de competitividad, y en las proyecciones realizadas por el sector para 2025.

\section{A modo de cierre.}

La industria farmacéutica argentina se ha destacado desde las últimas décadas por su performance productiva y su capacidad de aprovisionamiento a la región. Los recientes acuerdos celebrados con países desarrollados para la producción local de alguna de las fases de las vacunas para combatir e COVID-19, pueden repercutir favorablemente en los principales vectores de competitividad, con un impacto positivo en los niveles de producción, en la inserción en los mercados internacionales, y en la generación de capacidades de innovación. Los acuerdos de producción de AstraZeneca, Sputnik V y Sinopharm, resultan entonces muy 
valiosos para alcanzar las proyecciones del sector, y componen una oportunidad inédita para constituir una plataforma para futuros desarrollos nacionales, fortalecer las capacidades productivas del sector, generar eslabonamientos y fundamentalmente para abastecer a la región de manera más equitativa. Es por ello que este trabajo compone la base de próximos estudios que buscarán profundizar e incluso ampliar el espectro de indicadores de competitividad, sin perder de vista la relevancia del tema tanto en lo que refiere a las posibilidades productivas, así como también a la capacidad de aprovisionamiento local y regional en un contexto sanitario de pandemia, que se ha abierto con la producción local de las vacunas anticovid.

\section{Referencias bibliográficas.}

Abrutzky, R. Bramuglia, C. y Godio, C. (2015). El perfil de la industria farmacéutica de la Argentina. Interrogantes a mediano plazo. Ciencia, Docencia y Tecnología; 26 (51), 102-130.

Azpeitia Soto, Í. (2019). Estudio de mercado. El mercado farmacéutico en Argentina 2019. ICEX España Exportación e Inversiones. Recuperado de: https://www.icex.es/icex/es/navegacion-principal/todos-nuestros-servicios/informacion-demercados/paises/navegacion-principal/el-mercado/estudiosinformes/DOC2019828720.html?idPais=AR

Blanco, D. (2021, 5 de mayo). Avanza el acuerdo entre la local Sinergium y el Gobierno para fabricar la vacuna Sinopharm. Infobae. Recuperado de: https://www.infobae.com/salud/ciencia/2021/05/05/los-laberintos-de-las-vacunas-contra-elcovid-19-en-la-argentina-avanza-el-acuerdo-entre-la-local-sinergium-y-el-gobierno-parafabricar-la-vacuna-sinopharm/

Carson, R., y Higgs, R. (1986). Case Method [with Commentary]. Journal of Medical Ethics; 12 (1), 36-39. Recuperado de: www.jstor.org/stable/27716443

Centenera, M (2021, 4 de junio). Argentina comenzará a producir la vacuna rusa Sputnik V. El País. Recuperado de: https://elpais.com/sociedad/2021-06-05/argentina-comenzara-aproducir-la-vacuna-rusa-sputnik-v.html

CEPAL (1995). Competitividad de las Empresas Latinoamericanas: Comportamiento Empresarial y Políticas de Promoción de Exportaciones. Documento de Trabajo; (38). Recuperado de: https://repositorio.cepal.org/handle/11362/9653

Cantafio, F. (2017). Medicamentos. Recuperado de: https://salud.gob.ar/dels/printpdf/132 
Castro, R. (1999). En busca del significado: supuestos, alcances y limitaciones del análisis cualitativo. Reflexiones teórico-metodológicas. Recuperado de: http://sgpwe.izt.uam.mx/pages/egt/Cursos/MetodoLiclll/8 Castro Subjetividad.pdf

Chudnovsky, D. y Porta, F. (1990). La Competitividad Internacional. Principales Cuestiones Conceptuales y Metodológicas. CENIT. Documento de Trabajo; (3).

CILFA (2020). La industria farmacéutica argentina: su carácter estratégico y perspectivas. Recuperado de: https://cilfa.org.ar/wp1/wp-content/uploads/2020/10/Presentacioninstitucional-CILFA-2020-VF.pdf

Cuello, M. (2021, en prensa). Más allá de la tragedia de los commons y los anticommons: las controversias sobre las patentes farmacéuticas en Argentina. En Dabat, G. Paz, S. Cuello, M. (Coords.) La competitividad argentina en la nueva revolución tecnológica. Buenos Aires: Universidad Nacional de Quilmes.

Cuello, M. Montenegro, A. y Franco, E. (2021, en prensa). Dinámica centro-periferia, acceso a medicamentos y propiedad intelectual en la pandemia por el COVID-19: entre la lógica privativa y la colaborativa. Revista Rumbos.

Devincenci, A. (2020, 12 de agosto). Cómo es AstraZeneca, el laboratorio que producirá la vacuna contra el coronavirus. Cronista. Recuperado de: https://www.cronista.com/aperturanegocio/empresas/Quien-es-AstraZeneca-el-laboratorio-que-producira-la-vacuna-contra-elcoronavirus-20200812-0006.html

Doryan, E. Sánchez, J. Pratt, L. Gutiérrez, F. Garnier, L. Monge, G. y Marshall, L. (1999). Competitividad y Desarrollo Sostenible: Avances Conceptuales y Orientaciones Estratégicas. Costa Rica: INCAE- CLACDS.

Esser, K. Hillebrand, W. Messne, D. y Meyer-Stamer, J. (1996). Competitividad Sistémica: Nuevo Desafío a las Empresas y a la Política. Revista de la CEPAL; (59), 39-52. Recuperado de:

https://repositorio.cepal.org/bitstream/handle/11362/12025/059039052 es.pdf?sequence=1\&is Allowed $=y$

Evenett, S. J. y Linley, M. (2021). How Much Vaccine Will Be Produced This Year? THE VACCINE PRODUCTION RAMP UP. Airfinity. Recuperado de: https://assets.ctfassets.net/poihmvxzgivq/6CByA6R814eCWbMrfxUDQ8/87651e3d53409b77c 07bb1e33e2a11ad/AF SGEPT TL3 20 May 2021.pdf 
Fajnzylber, F. (1988). Competitividad Internacional. Evolución y Lecciones. Revista de la CEPAL; (36), 7-24. Recuperado de: https://repositorio.cepal.org/bitstream/handle/11362/11714/036007024_es.pdf?sequence=1\&is Allowed $=y$

Guzmán, A. y Pluvia Zuñiga, M. (2004). Patentes en la industria farmacéutica de México: los efectos en la investigación, el desarrollo y en la innovación. Comercio Exterior, 54 (12), 11041121.

Klipphan, A (2021, 20 de abril). Cómo fue la negociación para producir la vacuna Sputnik V en Argentina: los detalles del proyecto. Infobae. https://www.infobae.com/politica/2021/04/20/como-fue-la-negociacion-para-producir-la-vacunasputnik-v-en-argentina-los-detalles-del-proyecto/

Marin Loaysa, C. E. (2021). Proceso de elaboración de una vacuna a partir de un principio activo sólido termolábil. Facultad de Ciencias Químicas. Recuperado de: http://repositorio.utmachala.edu.ec/bitstream/48000/16953/1/E-

\section{MARIN\%20LOAYZA\%20CARLOS\%20EDUARDO.pdf}

Moreira, A. (2020). Soberanía estatal y cooperación internacional. Reflejos del derecho internacional frente al desafío de la COVID-19. Cuadernos de Derecho Público; 8, 71-91.

Neiman, G. Quaranta, G. (2006). Los estudios de caso en la investigación sociológica. En Vasilachis de Gialdino (Comp.) Estrategias de investigación cualitativa (213 - 237). Buenos Aires: Gedisa.

OCDE (1992). Technology and The Economy. The Key Relationships. Paris: Technology/Economy Programme.

Otero, G. (2006). Competitividad: marco conceptual y análisis sectorial para la Provincia de Buenos Aires. Ministerio de Economía, Gobierno de la Provincia de Buenos Aires. Cuadernos de Economía; (74). 9-38.

Our World in Data (2021, 10 de junio). Coronavirus Pandemic (COVID-19). Recuperado de: https://ourworldindata.org/

Porter, M. (1990). The Competitive Advantage of Nations. HARVARD BUSINESS REVIEW; (2), 73-91. 
Prebisch, R. (1948). El desarrollo económico de la América Latina y algunos de sus principales problemas. CEPAL. Recuperado de: https://repositorio.cepal.org/bitstream/handle/11362/40010/4/prebisch_desarrollo_problemas.p $\underline{\mathrm{df}}$

Reolon, E. (2009). Proceso de producción de una vacuna. En Sitio Argentino de producción animal. Recuperado de: https://www.produccionanimal.com.ar/sanidad intoxicaciones metabolicos/sanidad en general/07-vacunas.pdf

Stasiejko, H. A. Tristany, S. R. Pelayo Valente, L. J. Edelmys Krauth, K. (2009). La triangulación de datos como criterio de validación interno en una investigación exploratoria. SEDICI, Repositorio de la Universidad Nacional de La Plata. Recuperado de: http://sedici.unlp.edu.ar/bitstream/handle/10915/17245/Documento completo .pdf?sequence $=1$

Tapias García, H. (2005). Capacidades tecnológicas: elemento estratégico de la competitividad. Revista Facultad de Ingeniería Universidad de Antioquia; (33), 97-119.

United States Trade Representative (USTR) (2020). 2020 SPECIAL 301 REPORT. Recuperado de: https://ustr.gov/sites/default/files/2020 Special 301 Report.pdf

Vielma, J., Buelvas N. Suárez, R. Gutiérrez, L. Chirinos, R. Pérez, I. Villarreal, J. Urdaneta, H. (2018). Esfuerzos para el desarrollo de vacunas y adyuvantes. ACTA BIOCLINICA; 8 (15). Recuperado de: http://bdigital2.ula.ve:8080/xmlui/bitstream/handle/654321/300/9972-29924-1SM\%20rev16\%20\%28\%20pag259-287\%29.PDF?sequence=1\&isAllowed=y 